\title{
X-ray diffraction analysis of electroerosive powder materials, obtained from waste of tungsten-free hard alloy grade KNT16
}

\author{
Vladimir Serebrovsky ${ }^{1}$, and Boris Sabel'nikov ${ }^{2 *}$ \\ ${ }^{1}$ Kursk State Agricultural Academy, 305021 Kursk, Russian Federation \\ ${ }^{2}$ Southwest State University, 305040 Kursk, Russian Federation
}

\begin{abstract}
This article presents a study of the phase composition of powder electroerosive materials of TFHA grade KNT16, obtained in ethyl alcohol. It was established that the main phases in the test sample are TiC, $\mathrm{MoNi}_{3}, \mathrm{Ni}$, Mo.
\end{abstract}

\section{Introduction}

Tungsten-free hard alloys (TFHA) or cermets are materials based not on tungsten carbide, but on another refractory compound (usually titanium carbide or carbonitride); the cementing phase is metals - nickel and / or cobalt, with hardening additives of transition metals 4, 5, 6 groups (Mo, W, Cr, Nb, etc.). These materials combine both ceramic properties (exceptional hardness and wear resistance, oxidation resistance, low adhesion to the material being processed) and metal properties (strength, impact resistance). KNT16 alloy is intended to replace the standard T15K6 alloy, and in some cases instead of VK8, T14K8, T30K4 and T5K10 alloys for semi-finishing and semi-rough turning with continuous cutting of carbon, low alloy and some structural steels.

The widespread use of TFHA KNT16 brand in various industries leads to a large accumulation of its waste requiring processing. Currently, there are methods that allow the processing of solid alloy wastes with a view to their reuse. However, the disadvantages of the known methods are increased energy consumption, multi-operation process [1-3].

The most promising method for processing any conductive material is the method of electroerosive dispersion (EED), which is distinguished by the ecological purity of the process and relatively low energy costs.

Carrying out the planned measures will solve the problem of waste disposal and their further use and thereby reduce the cost of production of the final product.

The aim of the work was to carry out X-ray diffraction analysis of electroerosive powder materials, obtained from wastes of tungsten-free hard alloy grade KNT16 in ethyl alcohol.

\section{Materials and Methods}

To obtain the powder from TFHA waste KNT16 grade (GOST 19052-80), an EED device, developed by the authors, was used [4]. The waste was loaded into a reactor filled with a working fluid - ethyl alcohol (GOST R 56389-2015), the process was carried out with the

\footnotetext{
* Corresponding author: sabelnikovboris1@mail.ru
} 
following electrical parameters: capacitance of discharge capacitors $25,5 \mu \mathrm{F}$, voltage $195-$ $205 \mathrm{~V}$, pulse repetition rate $95-105 \mathrm{~Hz}$.

The phase composition of the sample was studied by X-ray diffraction on a Rigaku Ultima IV diffractometer in $\mathrm{Cu}-\mathrm{K}_{\alpha}$ radiation (wavelength $\lambda=0,154178 \mathrm{~nm}$ ) using Soller slits (Fig. 1).

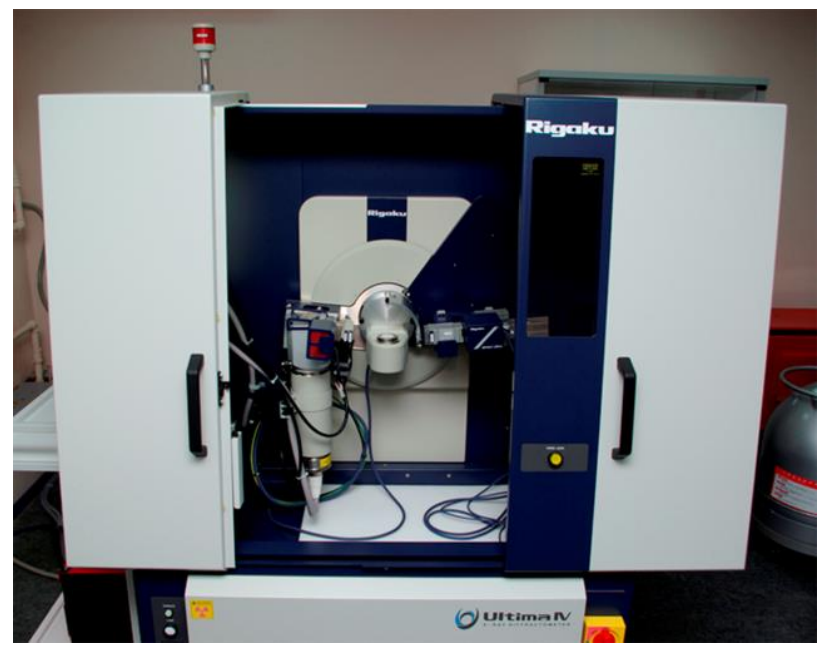

Fig.1. X-ray diffractometer Rigaku Ultima IV.

The diffraction spectrum for phase analysis is taken according to the $\theta-2 \Theta$ scanning scheme with focusing according to Bregt-Brentano in the range of angles of $5 \ldots 100$ degrees. $2 \Theta$. The shooting is carried out in dotted mode with a scanning step $\Delta(2 \theta)=0.02$ $\mathrm{deg}$, speed $0.6 \mathrm{deg} / \mathrm{min}$, operating voltage $45 \mathrm{kV}$, current $200 \mathrm{~mA}$ [5-11].

\section{Results}

To refine the profile of experimental X-ray diffraction patterns, the PDXL RIGAKU software package was used. The background was subtracted using the Sonneveld - Wisser method, the experimental profile was smoothed using the Savitsky - Naked method, and the components $k \alpha 1$ and $k \alpha 2$ were separated by the Rachinger method. To describe the diffraction maxima, a superposition of the Gauss function and the Lorentz function was used. The phase composition was determined using the ICCD PDF-2 database (2014).

The diffraction pattern and phase composition of the test sample are presented in Fig. 2 and Table 1.

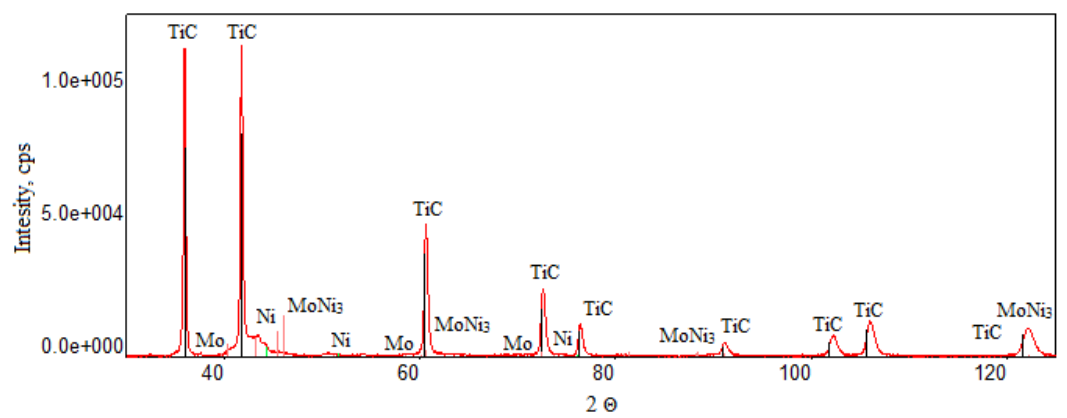

Fig.3. X-ray diffraction pattern of the test sample. 
Table 1. The phase composition of the test sample.

\begin{tabular}{|c|c|c|}
\hline Chemical formula & Type of crystal lattice & Lattice parameters \\
\hline TiC & $\begin{array}{c}225: \text { Fm-3m } \\
\text { cubic crystal lattice }\end{array}$ & $\mathrm{a}=\mathrm{b}=\mathrm{c}=4.323534 \AA$ \\
\hline $\mathrm{MoNi}_{3}$ & $\begin{array}{c}59: \text { Pmmn,choice-2 } \\
\text { orthorhombic crystal lattice }\end{array}$ & $\begin{array}{c}\mathrm{a}=5.167347 \AA, \\
\mathrm{b}=4.176675 \AA, \\
\mathrm{c}=4.360784 \AA\end{array}$ \\
\hline $\mathrm{Ni}$ & $\begin{array}{c}225: \text { Fm-3m } \\
\text { cubic crystal lattice }\end{array}$ & $\mathrm{a}=\mathrm{b}=\mathrm{c}=3.533749 \AA$ \\
\hline $\mathrm{Mo}$ & $\begin{array}{c}229: \mathrm{Im}-3 \mathrm{~m} \\
\text { cubic crystal lattice }\end{array}$ & $\mathrm{a}=\mathrm{b}=\mathrm{c}=3.135084 \AA$ \\
\hline
\end{tabular}

\section{Conclusion}

Based on the performed x-ray microanalysis, it was found that the main phases in electroerosive powder materials of the tungsten-free hard alloy KNT16 grade, obtained in ethyl alcohol, are TiC, MoNi3, Ni, Mo. The study will determine the most relevant area of application of the obtained samples and improve the quality of scientific and technological developments.

\section{References}

1. E.V. Ageev, Hardening technologies and coatings 6, 8-14, (2011)

2. R.A. Latypov, G.R. Latypova, E.V. Ageev, P.I. Burak, Int. Sci. J., 5, 80-86 (2013)

3. E.V. Ageev, Electromet., 10, 24-27 (2011)

4. E.V. Ageev, A. p. 2449859, Russian Federation, C2, B22F9/14 Installation for producing nanodispersed powders from conductive materials. - No. 2010104316/02; application 02/08/2010; publ. 05/10/2012

5. E.V. Ageeva, E.V. Ageev, N.M. Horyakova, Russ. Eng. Res., 35, 33-35 (2015)

6. E. V. Ageev, B. A. Semenikhin, R. A. Latypov, Fund. Prikl. Probl. Tekhn. Tekhnolog, 5, 39-42 (2010)

7. A. Pereverzev, E. Ageev, MATEC Web of Conf., 298, 00037 (2019)

8. E.V. Ageev, S.V. Khardikov, E.A. Vorobyev, A.A. Sysoev, MATEC Web of Conf., 298, 00127 (2019)

9. R.A. Latypov, E.V. Ageeva, G.R. Latypova, MATEC Web of Conf., 298, 00125 (2019)

10. E.V. Ageev, A.Yu. Altukhov, S.V. Khardikov, S.S. Gulidin, A.N. Novikov, J. NanoElectron. Phys., 7, 04080 (2015)

11. E.V. Ageev, A.Y. Altukhov, S.V. Khardikov, A.V. Kirichek, J. Nano- Electron. Phys., 8, 04055 (2016) 